\title{
Integrating New Staff into Endovascular Stroke-Treatment Workflows in the COVID-19 Pandemic
}

\author{
(D) M. Goyal, (D). Kromm, (D) A. Ganesh, (DC. Wira, (D) A. Southerland, (D).N. Sheth, (DH. Khosravani, (DP. Panagos, (D) N. McNair, \\ and (D).M. Ospel; On behalf of the AHA/ASA Stroke Council Science Subcommittees: Emergency Neurovascular Care (ENCC), \\ the Cardiovascular and Stroke Nursing Council, the Telestroke and the Neurovascular Intervention Committees
}

\begin{abstract}
SUMMARY: A health care crisis such as the coronavirus disease 2019 (COVID-19) pandemic requires allocation of hospital staff and resources on short notice. Thus, new and sometimes less experienced team members might join the team to fill in the gaps. This scenario can be particularly challenging in endovascular stroke treatment, which is a highly specialized task that requires seamless cooperation of numerous health care workers across various specialties and professions. This document is intended for stroke teams who face the challenge of integrating new team members into endovascular stroke-treatment workflows during the COVID19 pandemic or any other global health care emergency. It discusses the key strategies for smooth integration of new stroke-team members in a crisis situation: 1) transfer of key knowledge (simple take-home messages), 2) open communication and a nonjudgmental atmosphere, 3) strategic task assignment, and 4) graded learning and responsibility. While these 4 key principles should generally be followed in endovascular stroke treatment, they become even more important during health care emergencies such as the COVID-19 pandemic, when health care professionals have to take on new and additional roles and responsibilities in challenging working environments for which they were not specifically trained.
\end{abstract}

ABBREVIATIONS: COVID-19 = coronavirus disease 2019; EVT = endovascular treatment; ICU = intensive care unit

$\mathrm{T}$ he coronavirus disease 2019 (COVID-19) pandemic requires allocation of hospital staff and resources on short notice. As a consequence, new and sometimes less experienced team members might join the team to fill in the gaps. This scenario also applies to endovascular stroke treatment (EVT) workflows in the neuroangiography suite and post-EVT stroke care in the neuro-intensive care unit (Neuro-ICU) and stroke unit. There are several reasons

Received August 7, 2020; accepted after revision August 21.

From the Departments of Clinical Neurosciences (M.G., J.K., A.G., J.M.O.), Critical Care Medicine (..K.), and Diagnostic Imaging (M.G.), University of Calgary, Calgary, Alberta Canada; Department of Emergency Medicine and Stroke Program (C.W.) and Division of Neurocritical Care and Emergency Neurology (K.N.S.), Yale School of Medicine and Yale New Haven Hospital, New Haven, Connecticut; Departments of Neurology and Public Health Sciences (A.S.), University of Virginia, Charlottesville, Virginia; Neurology Quality and Innovation Laboratory (H.K.), Division of Neurology, Department of Medicine, Sunnybrook Health Sciences Centre, University of Toronto, Toronto, Ontario, Canada; Division of Emergency Medicine (P.P.), Washington University School of Medicine, St. Louis, Missouri; University of California (N.M.), Los Angeles, Los Angeles, California; and Department of Radiology (I.M.O.), University Hospital of Basel, Basel, Switzerland, On behalf of the AHA/ASA Stroke Council Science Subcommittees: Emergency

Neurovascular Care (ENCC), the Cardiovascular and Stroke Nursing Council, the Telestroke and the Neurovascular Intervention Committees.

Please address correspondence to Mayank Goyal, MD, Departments of Radiology and Clinical Neurosciences, Foothills Medical Centre, 1403 29th S. NW, Calgary, AB T2N2T9, University of Calgary, Calgary, AB, Canada; e-mail: mgoyal@ucalgary.ca; @mayank_G; @johanna_ospel

\section{- Indicates open access to non-subscribers at www.ajnr.org}

Indicates article with supplemental on-line table.

http://dx.doi.org/10.3174/ajnr.A6854 why new members might join EVT teams. For example, stroke team members with ICU experience might be redeployed to an ICU and have to be replaced, or team members might be quarantined because they had close contact with a patient with COVID19. Integrating new staff into EVT workflows is particularly challenging, given the time-critical nature of the disease, the need for seamless interdisciplinary and interprofessional cooperation, and the highly specialized skill sets of different team members.

This document is intended for stroke teams who face the challenge of integrating new staff into their EVT workflows during the COVID-19 pandemic or any other global health care emergency. It discusses strategies for smooth integration of new stroke-team members into EVT workflows in a crisis situation in 3 different settings: 1) the neuroangiography suite, 2) the NeuroICU ward, and 3) the stroke unit. The 4 overarching principles are the following: 1) transfer of key knowledge (simple takehome messages), 2) open communication and a nonjudgmental atmosphere, 3) strategic task assignment, and 4) graded learning and responsibility (Table 1 ). These 4 principles were developed during discussions among the members of the Emergency Neurovascular Care Committee, Cardiovascular and Stroke Nursing Council, and Telestroke and Neurovascular Intervention Committees and are mainly based on the joint experience of these committees. While it seems intuitively logical that those principles should generally be followed in clinical routine, and 


\begin{tabular}{|c|c|c|}
\hline Key Principle & Explanation/Implementation Strategy & Example \\
\hline $\begin{array}{l}\text { Transfer of key } \\
\text { knowledge }\end{array}$ & $\begin{array}{l}\text { New staff members should be primarily } \\
\text { taught the key principles of their new } \\
\text { working environment; these should be kept } \\
\text { as brief and concise as possible in order } \\
\text { not to overwhelm new staff }\end{array}$ & $\begin{array}{l}\text { Neuroangiography suite: never walk in the } \\
\text { room without a lead apron if a patient is } \\
\text { on the table } \\
\text { Neuro-ICU: never use a nasogastric tube until } \\
\text { proper placement has been confirmed by a } \\
\text { clinician (most commonly by a portable } \\
\text { chest x-ray) } \\
\text { Stroke unit: never feed a patient with stroke } \\
\text { with dysphagia solid food until a swallow } \\
\text { screen has been performed }\end{array}$ \\
\hline $\begin{array}{l}\text { Open communication } \\
\text { and nonjudgmental } \\
\text { atmosphere }\end{array}$ & $\begin{array}{l}\text { New staff members have to feel comfortable } \\
\text { telling core members if they do not feel } \\
\text { comfortable doing a certain task and } \\
\text { should not hesitate to ask for help or } \\
\text { advice }\end{array}$ & $\begin{array}{l}\text { A new staff member is told to monitor a } \\
\text { patient on an alteplase infusion but does } \\
\text { not know what symptoms or signs to look } \\
\text { for; he or she explains this to the } \\
\text { supervisor who reassigns the patient to a } \\
\text { more experienced member and helps train } \\
\text { the new member in this important task }\end{array}$ \\
\hline $\begin{array}{r}\text { Strategic task } \\
\text { assignment }\end{array}$ & $\begin{array}{l}\text { To avoid mistakes and treatment delays, new } \\
\text { team members should execute tasks that } \\
\text { are as closely related as possible to their } \\
\text { core field of expertise }\end{array}$ & $\begin{array}{l}\text { A nurse from the nephrology ward joins the } \\
\text { stroke team; he or she is familiar with } \\
\text { management of patient vitals but not with } \\
\text { neuroangiography-specific terminology, eg, } \\
\text { guidewire, balloon-guide catheter; thus, the } \\
\text { task should be focused on management of } \\
\text { patient vitals rather than procedure- } \\
\text { specific peculiarities }\end{array}$ \\
\hline $\begin{array}{l}\text { Graded responsibility } \\
\text { and learning }\end{array}$ & $\begin{array}{l}\text { New staff members should gradually take on } \\
\text { new tasks and responsibilities; they should } \\
\text { feel comfortable performing a certain task } \\
\text { and be capable of executing it safely } \\
\text { before they are assigned additional, more } \\
\text { complicated tasks }\end{array}$ & $\begin{array}{l}\text { A schedule that pairs shifts of new team } \\
\text { members with core team members; new } \\
\text { team members are intermixed in new roles, } \\
\text { as they have to learn new and complex } \\
\text { tasks }\end{array}$ \\
\hline
\end{tabular}

particularly when caring for patients with acute stroke, doing so becomes even more critical during health care emergencies such as the COVID-19 pandemic because in such a situation, health care professionals have to take on new and additional roles and responsibilities in challenging working environments for which they were not specifically trained.

This document is also intended to encourage and empower working groups and institutions to create a framework for fast decision-making in crisis situations. In the following, we summarize key knowledge, unique characteristics (ie, tasks that are not ideal for new team members), and generic aspects (ie, tasks that lend themselves to new team members because they can extrapolate their experience from their previous working environment) for acute stroke care in 3 different settings: the neuroangiography suite (Table 2), Neuro-ICU (Table 3), and stroke unit (Table 4). We believe that in a crisis such as the COVID-19 pandemic, the focus should be on the generic aspects of stroke care: New team members can build on their pre-existing knowledge and skills and therefore contribute best to guideline-based stroke care. ${ }^{1}$ Given their greater experience, it might be reasonable to primarily assign stroke and particularly EVT-specific tasks to the "core members" of the stroke team.

\section{Neuroangiography Suite}

The neuroangiography environment differs from the NeuroICU and stroke unit in that the patient with stroke remains there for only a short time. The risk of radiation exposure and handling of thrombectomy equipment is unique to the neuroangiography suite and yields additional challenges for new staff members. Furthermore, the neuroangiography staff has to execute several highly specialized technical tasks, such as positioning of the neuroangiography table and preparing the appropriate catheters and thrombectomy devices. Because chances of good outcome rapidly decrease with increasing time to reperfusion, workflows in the neuroangiography suite need to be maximally time-efficient. Examples of more generic tasks in the neuroangiography suite that would be suitable for new stroketeam members would be managing IV lines and blood pressure monitoring, while management of access-site complications, handling of endovascular devices, and reconstruction and labeling of angiography images should preferably be performed by key staff members (Table 2).

\section{Neuro-ICU and Stroke Unit}

Acute ischemic stroke treatment does not stop once the occluded vessel has been opened. Post-EVT care on the Neuro-ICU and stroke unit is critical to support patient recovery and prevent poststroke complications, which may erase the benefits of EVT. ${ }^{2}$ Typical Neuro-ICU and stroke units share many similarities, whereas stroke units often represent a "step-down" environment in which patients may be at risk of requiring escalation to critical care. A collaborative multidisciplinary team environment with effective role 
Table 2: Take-home points for new staff and unique-versus-generic aspects of stroke care in the neuroangiography suite

\begin{tabular}{lll}
\hline $\begin{array}{c}\text { Most Important Teaching Points (Take- } \\
\text { Home Points) for New Team Members }\end{array}$ & $\begin{array}{c}\text { Unique Characteristics of the } \\
\text { Neuroangiography Suite Environment } \\
\text { (Not Ideal Tasks for New Team Members) }\end{array}$ & $\begin{array}{c}\text { Generic Aspects of the Neuroangiography } \\
\text { Suite Environment That Are Similar to Those } \\
\text { in Other Medical Areas (Appropriate Initial } \\
\text { Tasks for New Team Members) }\end{array}$ \\
\hline Radiation awareness & Handling the groin puncture/access site & $\begin{array}{c}\text { Blood pressure control, hemodynamic } \\
\text { monitoring }\end{array}$ \\
$\begin{array}{c}\text { Boundaries between sterile vs nonsterile } \\
\text { environment }\end{array}$ & Handling of catheters and devices & Management of IV lines \\
$\begin{array}{c}\text { Location of key emergency drugs and } \\
\text { equipment (epinephrine, oxygen, } \\
\text { intubation kit), key/safe combinations in } \\
\text { case some drugs (eg, opiates) are stored } \\
\text { in a safe }\end{array}$ & Navigating the angiography machine & $\begin{array}{c}\text { Clinical monitoring of the patient during the } \\
\text { procedure }\end{array}$ \\
$\begin{array}{c}\text { Phone numbers and schedule of } \\
\text { neurointerventionalists, anesthesiologists, } \\
\text { techs, and nurses on call }\end{array}$ & Image reconstruction and labeling & Documentation of patient status \\
\hline
\end{tabular}

Table 3: Take-home points for new staff and unique-versus-generic aspects of stroke care in the Neuro-ICU

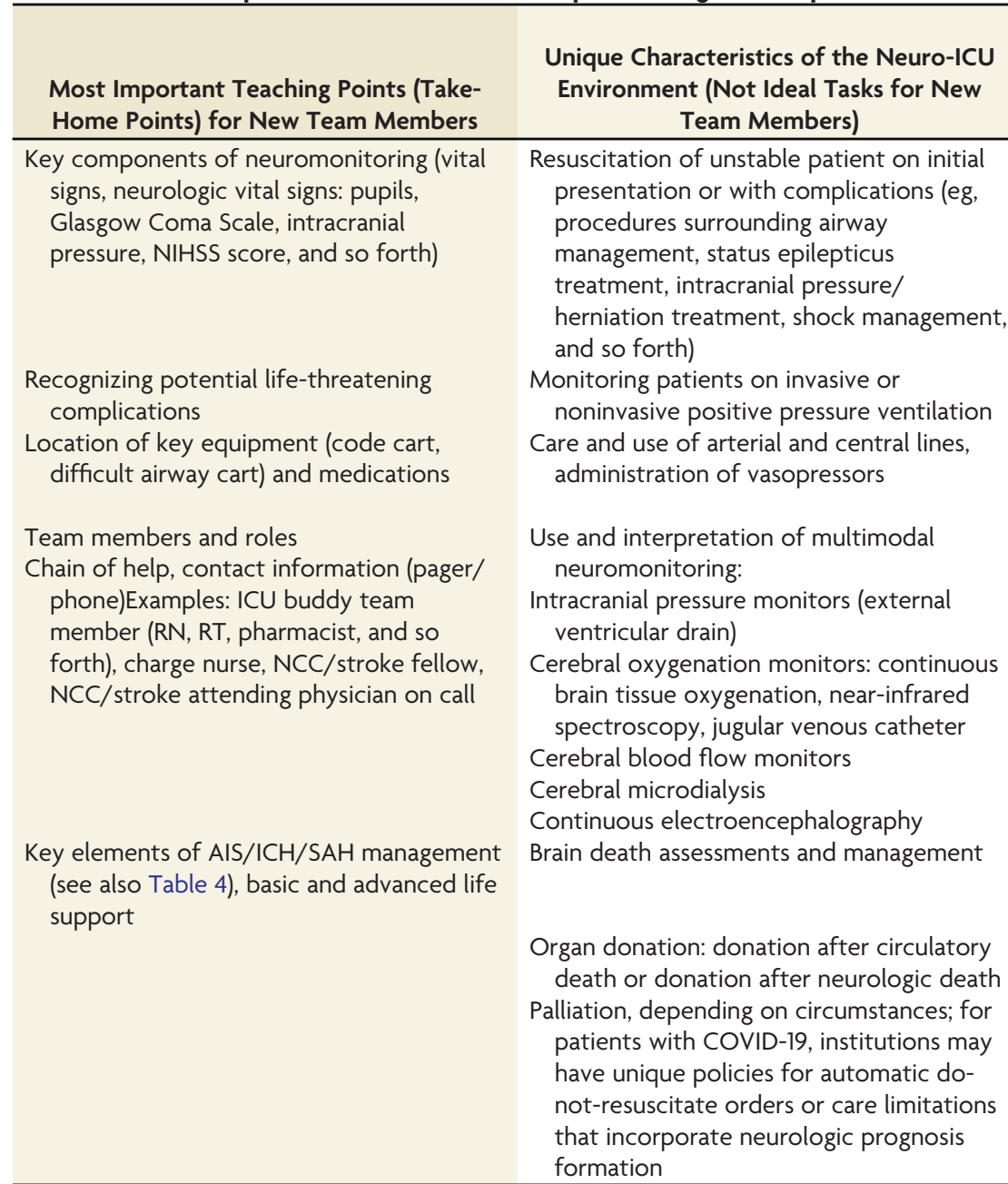

Generic Aspects of the Neuro-ICU

Environment That Are Similar to Those in Other Medical Areas (Appropriate Initial Tasks for New Team Members)

Monitoring vital parameters, level of consciousness, and respiratory parameters of nonintubated patients

Management of enteral feeds and IV fluids

Basic medication administration (may include managing alteplase/tenecteplase infusions, depending on background)

Placement and care of nasogastric/ orogastric tube, IV line, Foley catheter, and so forth

Bathing, turning, mobilizing patients

Charting/documentation of patient course

Note:-RN indicates registered nurse; RT, respiratory therapist; NCC, neurocritical care; AIS, acute ischemic stroke; ICH, intracerebral hemorrhage.

${ }^{a}$ For specific Neuro-ICU take-home points for the management of patients with acute ischemic stroke, intracranial hemorrhage, and subarachnoid hemorrhage, see Online Table.

delegation is the cornerstone of both the Neuro-ICU and stroke unit, with most roles being quite similar (Figure), with the notable absence of respiratory therapists in most stroke units. Neuro-ICU tasks that lend themselves to new team members are, for example, placement of nasogastric and orogastric tubes and Foley catheters, while more ICU-specific aspects such as vasopressor therapy and optimization of positive pressure ventilation parameters should ideally remain with the core team members 


\begin{tabular}{|c|c|c|}
\hline $\begin{array}{l}\text { Most Important Teaching Points (Take- } \\
\text { Home Points) for New Team Members }\end{array}$ & $\begin{array}{c}\text { Unique Characteristics of the Stroke Unit } \\
\text { Environment (Not Ideal Tasks for New } \\
\text { Team Members) }\end{array}$ & $\begin{array}{c}\text { Generic Aspects of the Stroke Unit } \\
\text { Environment Similar to Other Medical } \\
\text { Areas (Appropriate Initial Tasks for New } \\
\text { Team Members) }\end{array}$ \\
\hline $\begin{array}{l}\text { Recognizing an acute stroke, recurrent } \\
\text { stroke, and abrupt neurologic } \\
\text { deterioration of recent ischemic or } \\
\text { hemorrhagic stroke }\end{array}$ & $\begin{array}{l}\text { Monitoring a patient in the unit after } \\
\text { receiving IV alteplase (involves watching } \\
\text { for angioedema, bleeding, frequent } \\
\text { neurologic vital sign monitoring, close } \\
\text { blood pressure control, and so forth) }\end{array}$ & $\begin{array}{l}\text { Obtaining/interpreting scheduled vital signs } \\
\text { (temperature, blood pressure, heart rate, } \\
\text { respiratory rate, oxygen saturation) and } \\
\text { point-of-care blood glucose in patients }\end{array}$ \\
\hline $\begin{array}{l}\text { Managing infusions of alteplase for stroke or } \\
\text { of heparin (eg, for intraluminal } \\
\text { thrombosis, venous sinus thrombosis) }\end{array}$ & $\begin{array}{l}\text { Being part of the acute stroke thrombolysis } \\
\text { team (being comfortable with the "code } \\
\text { stroke" and mixing alteplase) }\end{array}$ & $\begin{array}{l}\text { Foley catheter insertion, urinary dipstick } \\
\text { testing, and identification of potential } \\
\text { urinary tract infection }\end{array}$ \\
\hline $\begin{array}{l}\text { Grossly identifying patients who are } \\
\text { potentially aspirating versus those safe to } \\
\text { swallow }\end{array}$ & $\begin{array}{l}\text { Managing a patient at risk of malignant } \\
\text { middle cerebral artery or cerebellar } \\
\text { stroke (involves closely watching for } \\
\text { neurologic deterioration and liaising with } \\
\text { stroke/neurosurgery team for potential } \\
\text { decompressive craniectomy) }\end{array}$ & $\begin{array}{l}\text { Managing the patient's routine medications } \\
\text { and reconciling them with those taken } \\
\text { preadmission }\end{array}$ \\
\hline $\begin{array}{l}\text { NG insertion, feeding, and NG medication } \\
\text { administration }\end{array}$ & $\begin{array}{l}\text { Managing a patient with a major intracranial } \\
\text { hemorrhage (involves watching for } \\
\text { emerging symptoms of hydrocephalus or } \\
\text { major hematoma expansion that may } \\
\text { warrant neurosurgical intervention or ICU } \\
\text { transfer) }\end{array}$ & $\begin{array}{l}\text { Caring for a patient in the subacute-to- } \\
\text { chronic poststroke period with/without } \\
\text { medical issues like urinary tract infection, } \\
\text { cellulitis, or pressure ulcers }\end{array}$ \\
\hline Performing a NIHSS bedside examination & $\begin{array}{l}\text { Receiving a patient after thrombectomy } \\
\text { (involves monitoring the groin puncture } \\
\text { site or managing hematoma) }\end{array}$ & $\begin{array}{l}\text { Evaluation and initial management of a } \\
\text { patient with chest pain or shortness of } \\
\text { breath (eg, poststroke myocardial } \\
\text { infarction, aspiration pneumonia) }\end{array}$ \\
\hline $\begin{array}{l}\text { Pager or phone numbers and schedule of } \\
\text { stroke fellows and neurologists on call }\end{array}$ & $\begin{array}{l}\text { Receiving a patient after carotid } \\
\text { endarterectomy (involves watching for } \\
\text { reperfusion complications, lower cranial } \\
\text { neuropathies interfering with swallowing) }\end{array}$ & $\begin{array}{l}\text { Evaluation and initial management of a } \\
\text { patient with deep vein thrombosis }\end{array}$ \\
\hline $\begin{array}{l}\text { Understanding basic stroke mechanisms for } \\
\text { early secondary prevention }\end{array}$ & $\begin{array}{l}\text { Defining a stroke mechanism through a } \\
\text { sophisticated understanding of } \\
\text { neurovascular anatomy, localization, and } \\
\text { cerebrovascular syndromes }\end{array}$ & $\begin{array}{l}\text { Working with patient and pharmacy to } \\
\text { ensure proper dosing and administration } \\
\text { of early secondary stroke prevention (eg, } \\
\text { antithrombotics, statin therapy, blood } \\
\text { pressure regimen, smoking cessation) }\end{array}$ \\
\hline
\end{tabular}

Note:-NG indicates nasogastric tube.

(Table 3). In the stroke unit, new staff might want to start with managing patients' routine medication and Foley catheter and IV-lines, while obtaining a detailed neurologic status such as the NIHSS would be a more suitable task for experienced team members (Table 4). Nevertheless, it would certainly be desirable for the newer team members to initiate structured training regarding stroke-specific tasks (eg, NIHSS score) under the guidance of pre-existent staff members as would be the local standard at that institution.

Simulation training ("dry" practice runs with a nurse or mannequin acting as the patient) can help to practice specific workflow steps, identify latent safety threats, and familiarize new team members with their new tasks. ${ }^{3}$ Simulation team training has also been shown to improve team functioning-communication and cooperation of different members among a medical team. ${ }^{4,5}$ This is particularly important for workflow in the neuroangiography suite because treatment delays at this stage will lead to delayed reperfusion and thereby directly affect patient outcome. It is important to establish continuous monitoring of treatment quality (eg, reperfusion quality and access site complications such as groin hematomas and infections following endovascular treatment) and workflow times (door-to-needle times, door-to-groin puncture times), particularly in a health care crisis, to ensure that treatment quality is maintained to the best of the ability of the system and to detect problems in EVT workflows and treatment quality early on, which grants the medical team the opportunity to intervene in a timely manner. One might be tempted to think that continuous performance monitoring for complex, multidimensional tasks involving numerous specialties as is the case in endovascular stroke treatment is impractical, but studies have repeatedly shown that team performance in medicine can be validly measured across complex settings and that doing so helps to improve treatment workflow. ${ }^{6}$

\section{CONCLUSIONS}

Endovascular stroke treatment reaches well beyond the neuroangiography suite and encompasses a wide range of specialties (neurology, neuroradiology, neurosurgery, anesthesia, intensive care) and designations (physicians [among them attendings, fellows, and residents], nurses, technologists, pharmacists, therapists, nutritionists, medical students, nurse practitioners, physician assistants), just to name a few. During the COVID-19 pandemic and other major health care emergencies, augmentation of staff from other areas may be required due to staff redeployment, staff exposures/ required quarantines, and increased patient demands. ${ }^{7}$ This carries the risk of decreasing the quality of EVT and post-EVT care. ${ }^{8}$ 


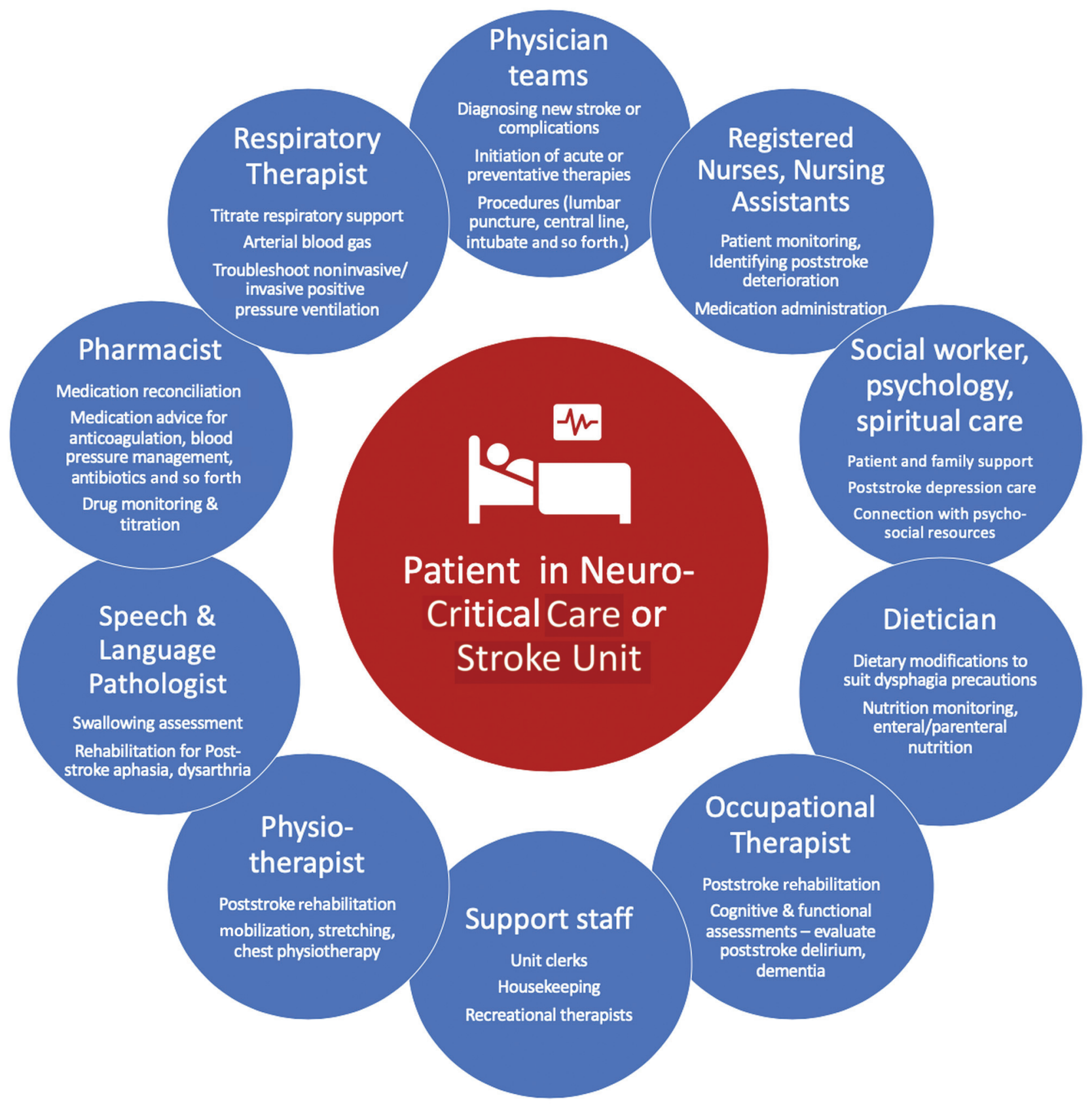

FIGURE. A model of patient-centered multidisciplinary care in the Neuro-ICU or stroke unit that is both helpful and reassuring for new staff members. The model is quite similar in both the neuro-critical care and stroke units with the notable exception of respiratory therapists who are often not part of medical stroke units. While this model is, of course, generalizable to nonstroke settings as well, some specific examples are illustrated to show how different members of the team may synergistically address a stroke-related problem. For example, in a patient with dysphagia, the nursing or physician team may be the first to notice a poststroke deterioration with the patient choking or coughing during a simple trial. This prompts the team to involve the speech and language pathologist who confirms poststroke dysphagia and recommends a temporary nasogastric tube, which is inserted by a nurse (perhaps with a new nursing team member observing this common task), with the dieticians then helping ensure that the nasogastric feed provided meets the patient's feeding requirements, potentially monitoring for a refeeding syndrome. These changes may be overwhelming for the patient and family, prompting the team to involve psychology to assess poststroke depression as well as social work and spiritual care to connect the patient and family to key resources.

Maintaining timely and comprehensive endovascular stroke care at a high quality during a health care crisis such as the COVID-19 pandemic is of utmost importance. Of note, the framework that was outlined in this article for integration of new members into existing stroke teams is based on personal experience of the
American Heart Association/American Stroke Association Stroke Council Science Subcommittee members rather than objective data. Nevertheless, we would like to encourage individual stroke teams and their hospitals to collect data from their COVID-19 experience and publish them, because this would provide valuable information 
to stroke teams and help them to further improve EVT workflows and post-EVT care in similarly challenging situations.

Disclosures: Aravind Ganesh-UNRELATED: Consultancy: MD Analytics, My Medical Panel, Adkins Research Group, and Genome BC; Grants/Grants Pending: Rhodes Trust, Wellcome Trust, the University of Calgary, Alberta Innovates, the Canadian Cardiovascular Society, and the Canadian Institutes of Health Information; Payment for Lectures Including Service on Speakers Bureaus: National Health Service Health Education England; Patents (Planned, Pending Or Issued): a provisional patent application (US 63/024,239) for a system to deliver remote ischemic conditioning or other cuff-based therapies; Stock/ Stock Options: SnapDx, TheRounds.ca, and Advanced Health Analytics; Travel/ Accommodations/Meeting Expenses Unrelated to Activities Listed: University of Calgary; OTHER RELATIONSHIPS: unpaid membership in the editorial boards of Neurology, Neurology: Clinical Practice, and Stroke. Andrew SoutherlandRELATED: Consulting Fee or Honorarium: Legal Expert Consultation, paid to the University of Virginia Physicians Group on his behalf. UNRELATED: Board Membership: Neurology Podcast, Comments: I served as past section editor of the journal Neurology Podcast; I completed the paid role in 2018; Consultancy: NeurovView Diagnostics, Comments: unpaid consultancy, work completed; Employment: University of Virginia Health System; Expert Testimony: legal expert consultation, Comments: I provide expert legal review for vascular neurology and stroke cases, both plaintiff and defense work*; Grants/Grants Pending: Diffusion Pharmaceuticals, Comments: Principal Investigator, PHASTTSC Trial, https://clinicaltrials.gov/ct2/show/NCT03763929*; Patents (Planned, Pending or Issued): US Patent Application No. 14/910,890 (iTREAT), US Provisional Patent Application No. 62/620,096 (BANDIT), Comments: patents pending. Peter Panagos_RELATED: Grant: National Institutes of Health/National Institute of Neurological Disorders and Stroke*; UNRELATED: Employment: Washington University. Norma McNair-UNRELATED: Board Membership: American Board of Neuroscience Nursing, Comments: reimbursement for travel expenses only, no payment. Kevin N. Sheth-UNRELATED: Consultancy: Ceribell, ZOLL; Grants/Grants Pending: National Institutes of Health, American Heart Association, Biogen, Bard, Novartis, Hyperfine; Stock/Stock Options: Alva. *Money paid to the institution.

\section{REFERENCES}

1. Powers WJ, Rabinstein AA, Ackerson T, et al. Guidelines for the Early Management of Patients with Acute Ischemic Stroke: 2019 Update to the 2018 Guidelines for the Early Management of Acute Ischemic Stroke-A Guideline for Healthcare Professionals from the American Heart Association/American Stroke Association. Stroke 2019;50:e344-418 CrossRef Medline

2. Ganesh A, Menon BK, Assis ZA, et al. Discrepancy between posttreatment infarct volume and 90-day outcome in the ESCAPE randomized controlled trial. Int J Stroke 2020 June 9. [Epub ahead of print] CrossRef Medline

3. Patterson MD, Geis GL, Falcone RA, et al. In situ simulation: detection of safety threats and teamwork training in a high risk emergency department. BMJ Qual Saf 2013;22:468-77 CrossRef Medline

4. Buljac-Samardzic $M$, Doekhie KD, van Wijngaarden JDH. Interventions to improve team effectiveness within health care: a systematic review of the past decade. Hum Resour Health 2020;18:2 CrossRef Medline

5. Kurz MW, Ospel JM, Advani R, et al. Simulation methods in acute stroke treatment: current state of affairs and implications. Stroke 2020;51:1978-82 CrossRef Medline

6. Rosen MA, DiazGranados D, Dietz AS, et al. Teamwork in healthcare: key discoveries enabling safer, high-quality care. Am Psychol 2018;73:433-50 CrossRef Medline

7. Qiu H, Tong Z, Ma P, et al; China Critical Care Clinical Trials Group (CCCCTG). Intensive care during the coronavirus epidemic. Intensive Care Med 2020;46:576-78 CrossRef Medline

8. Lee A, Cheung YSL, Joynt GM, et al. Are high nurse workload/staffing ratios associated with decreased survival in critically ill patients? A cohort study. Ann Intensive Care 2017;7:46 CrossRef Medline 